\title{
Apresentação de uma Metodologia de Avaliação Baseada em Rubricas para Avaliação de Trabalhos de Conclusão de Curso no Curso de Engenharia da Computação
}

\author{
Eduardo Juliano Alberti* \\ Veronica Isabela Quandt ${ }^{*}$ \\ Caroline Mazetto Mendes* \\ eduardojalberti@gmail.com \\ veronica.quandt@gmail.com \\ carol.mazetto@gmail.com \\ Universidade Positivo \\ Curitiba, Paraná
}

\author{
Luiz Alberto Bordignon \\ Felipe Augusto Przysiada \\ Leonardo Gomes Tavares \\ luiz.bordignon@up.edu.br \\ felipe.przysiada@up.edu.br \\ leonardo.tavares@up.edu.br \\ Universidade Positivo \\ Curitiba, Paraná
}

\section{RESUMO}

O TCC é o momento no qual os alunos empregam suas habilidades técnicas e comportamentais para o desenvolvimento de um projeto multidisciplinar a fim de atingir um objetivo. Por ser a Engenharia de Computação uma área-meio, cabe aos alunos conhecer o contexto, as especificidades da área e problemática que desejam solucionar. Assim, professores e gestores devem fornecer métodos e ferramentas que permitam e favoreçam o desenvolvimento, acompanhamento e avaliação de competências necessárias para o desenvolvimento de projetos deste nível. Para tal, propõem-se um método cujas avaliações compreendem o uso de rubricas para análise de competências. Este método engloba 5 fases de trabalho: Proposta, Revisão Bibliográfica, Especificação Técnica ou Metodologia de Pesquisa, Desenvolvimento e Conclusão. Os alunos são avaliados, por meio de rubricas, que permitem acompanhar o desenvolvimento das competências necessárias para cada uma das etapas. Cada rubrica utiliza critérios, classificáveis em níveis de performance, para indicar as habilidades de uma ou mais competências. Ao final de cada ciclo, critérios, níveis de performance, fases e modelos de documentos são analisados e modificados conforme indicações do corpo docente, garantindo um processo de melhoria contínua da metodologia. Para avaliar o método proposto, professores e alunos responderam a um questionário onde classificaram os níveis de importância, em ordem de 0 a 10, da existência das rubricas $(7,43 \pm 2,47$ para alunos; $8,50 \pm 3,20$ para professores $)$, da conexão entre critérios e fases $(8,07 \pm 1,49$ para alunos; $8,17 \pm 1,72$ para professores) e da clareza e assertividade dos indicadores ou níveis de desempenho (7,93 $\pm 1,33$ para alunos; 7,17 $\pm 2,14$ para professores).

*Autores contribuíram igualmente para esta pesquisa.

Fica permitido ao(s) autor(es) ou a terceiros a reprodução ou distribuição, em parte ou no todo, do material extraído dessa obra, de forma verbatim, adaptada ou remixada, bem como a criação ou produção a partir do conteúdo dessa obra, para fins não comerciais, desde que sejam atribuídos os devidos créditos à criação original, sob os termos da licença CC BY-NC 4.0.

EduComp'21, Abril 27-30, 2021, Jataí, Goiás, Brasil (On-line)

(c) 2021 Copyright mantido pelo(s) autor(es). Direitos de publicação licenciados à Sociedade Brasileira de Computação (SBC).

\section{PALAVRAS-CHAVE}

Trabalho de Conclusão de Curso, Metodologia de avaliação, Rubricas

\section{INTRODUÇÃO}

O trabalho de conclusão de curso (TCC) é um documento que apresenta os resultados de um estudo ou projeto relacionado ao curso de graduação do estudante. O TCC deve apresentar, entre outros tópicos, o desenvolvimento do trabalho e a discussão dos resultados, e deve expressar conhecimento do assunto escolhido e estar alinhado com o conteúdo programático do curso em que o estudante está inserido, além de ser interdisciplinar em sua aplicação. O TCC deve ser realizado sob supervisão de um professor orientador, com titulação mínima à do grau pretendido pelo estudante.

O TCC dá ao estudante a oportunidade de aplicar todo o conhecimento adquirido durante o curso de graduação. É uma experiência fundamental para a formação do estudante, já que traz a oportunidade de resolução de problemas reais detectados no cotidiano, aplicando suas habilidades técnicas, comportamentais e multidisciplinares [6].

O TCC é, muitas vezes, o primeiro resultado do esforço de um pesquisador, sendo seguido, por exemplo, de dissertação de mestrado, tese de doutorado, publicações em periódicos, congressos etc. onde o educando se torna responsável pela construção do próprio conhecimento. O TCC é um estímulo à pesquisa dentro do curso de engenharia, principalmente pelas fases que permeiam o seu desenvolvimento [5].

Além do desenvolvimento do TCC, durante um período regulamentado pela Instituição de Ensino Superior (IES), ao final o estudante deve entregar um trabalho escrito, que costuma ser regulamentado pela norma NBR 14724, que estabelece os princípios gerais para construção de trabalhos acadêmicos. Seu foco está na apresentação dos elementos para bancas ou outras formas de comissões julgadoras [1].

A atualidade requer dos engenheiros recém-formados, que possuam domínio técnico em sua área, tenham conhecimentos multidisciplinares e sejam portadores de uma visão globalizada. Este perfil pode ser construído na fase de desenvolvimento do TCC [15].

O processo que envolve o tema de avaliação de todo o processo de um TCC deve passar por constantes análises e reformulações, 
a fim de conseguir extrair o máximo dos objetivos esperados dele. Pensando nisso, parece ser de grande valia a utilização de rubricas para tal avaliação. Já que uma rubrica consiste em um documento que articula expectativas e objetivos de uma avaliação em uma lista de critérios que auxiliam na descrição de níveis de qualidade no processo avaliativo [9].

As rubricas podem facilitar a comunicação entre docentes e discentes, trazendo um feedback objetivo e eficiente, pois possibilitam a visualização do desempenho ajudando na objetividade docente para o entendimento do que foi, e do que não foi, atingido como objetivo, e em qual amplitude [9].

Desta forma, este trabalho visa apresentar uma metodologia, baseada em rubricas, desenvolvida e adotada no curso de Engenharia da Computação da Universidade Positivo. Serão discutidos quais os papéis no processo do TCC, o modelo de avaliação, as etapas, e os resultados já obtidos durante os anos de 2018, 2019 e 2020.

\section{TRABALHOS RELACIONADOS}

A avaliação baseada em rubricas tem sido utilizada em diferentes atividades acadêmicas na área da Computação. Contudo, observa-se que há poucos exemplos de aplicação dessa metodologia na avaliação de trabalhos de conclusão de curso. As principais iniciativas nacionais nos cursos de Computação são apresentas a seguir.

Roque, Elia e da Motta mostraram a utilização de rubricas na avaliação de aprendizagem em ambientes de educação à distância [14]. O trabalho apresenta uma experiência realizada com o modelo MOSAICO (Modelo Sistêmico de Avaliação para Internet baseado em competência). Para exemplificar o uso de rubricas no modelo MOSAICO, utilizou-se um fórum de debates em uma atividade colaborativa, em um curso ministrado pelo Núcleo de Computação Eletrônica da Universidade Federal do Rio de Janeiro (UFRJ). Os critérios de avaliação da rubrica são relacionados a competência de transmitir informação e se comunicar. Os autores comentam que, ao descrever os níveis de desempenho para cada critério, os professores acabaram por refletir sobre a avaliação, aperfeiçoando a prática pedagógica.

De Oliveira et al. propuseram uma estratégia de reconhecimento automático de representações de rubricas a partir de soluções de exercícios de programação feitas por alunos [8]. O sistema proposto implementa uma combinação das técnicas de Análise de Componentes Principais e Clustering. Para tal, o professor participa de um processo de aprendizagem ativa, usando rubricas para avaliar soluções selecionadas pelo sistema. A estratégia proposta contribui para auxiliar o trabalho de avaliação realizado pelo professor ao gerar automaticamente representações de rubricas, as quais possibilitam um retorno mais claro e objetivo aos estudantes de programação.

Oliveira et al. apresentam uma metodologia de ensino baseada na combinação das técnicas de avaliação colaborativa e rubrica, a fim de prover o desenvolvimento de habilidades de comunicação escrita [12]. A metodologia foi aplicada no curso de Engenharia da computação da Universidade Federal de São Paulo (Unifesp), na disciplina de Laboratório de Arquitetura e Organização de Computadores. Nessa disciplina, os alunos devem confeccionar um relatório técnico, o qual é avaliado por meio de um processo de avaliação colaborativa e uso de rubricas. Os resultados mostram que houve uma maior preocupação dos alunos na elaboração de melhores relatórios, além da melhora na percepção dos alunos sobre a qualidade educacional da disciplina.

Santos, Pazini e Kemczinski realizaram um mapeamento sistemático da literatura sobre a avaliação por pares das competências de um indivíduo em uma equipe de projeto de software [7]. A maioria dos artigos encontrados na pesquisa são da área educacional, em comparação a área empresarial. Observou-se que a rubrica é amplamente utilizada para medir a avaliação por pares, em comparação a outras ferramentas. Os autores ressaltam que a avaliação por competências ainda requer estudos, considerando a sua importância no contexto de trabalhos em equipe.

Caritá et al. apresentam o uso de rubrica numa disciplina semipresencial do curso de Engenharia de Produção [4]. A rubrica foi utilizada para a avaliação de atividades extraclasse realizadas pelos alunos. Em uma das atividades, por exemplo, foram abordados temas como Big Data e Internet das Coisas. Os autores ressaltam que por meio da rubrica os alunos conseguem estimar a sua nota previamente, enquanto os professores conseguem avaliar as atividades de forma objetiva. Além disso, os autores comentam que rubrica minimiza pedidos de recorreções das avaliações, já que os critérios são explícitos para os alunos.

Sobre o uso de rubricas em trabalho de conclusão de curso, Ferraz apresentou uma experiência aplicada no curso de Comunicação Visual [11]. O processo é realizado etapas, as quais incluem planejamento e desenvolvimento. São ao todo quatro etapas, uma em cada bimestre do ano letivo, totalizando um ano para realização e apresentação do trabalho. Os resultados mostram que a abordagem torna os critérios avaliativos mais claros e coerentes aos objetivos de aprendizagem. Também, permite que os alunos possam revisar e reavaliar o trabalho durante todo o processo. Por fim, observou-se que uso da rubrica pode auxiliar os professores a pensarem com cuidado e de forma crítica sobre o que estão ensinando e que os alunos devem aprender.

\section{CONTEXTO HISTÓRICO}

O curso de Engenharia da Computação da Universidade Positivo, criado em 1999, sempre possuiu um caráter formativo dinâmico, moderno e voltado, com maior peso, ao ensino da eletrônica com foco em sistemas embarcados. Seu objetivo educacional esteve voltado à formação de profissionais dotados de pensamento crítico e capazes de adaptar-se às constantes, e cada vez mais globais, mudanças tecnológicas e de paradigmas [10].

O dinamismo da área, porém, sempre exigiu um forte trabalho do corpo docente para estabelecer rápidas e sólidas conexões entre os conceitos teóricos e as técnicas computacionais. Além disso, a preocupação com a formação integral, desenvolvendo também características comportamentais, historicamente foi traduzida em ações como a prática de projetos transdisciplinares [16], a implementação de avaliações de objetivos educacionais [13], a relação multidisciplinar entre disciplinas [3] e o uso de metodologias ativas no processo ensino-aprendizagem [2].

Tais iniciativas, porém, não se limitaram à formação de alunos voltados ao mercado profissional, mas também preocupados em investir em carreiras voltadas à pesquisa e inovação. Ao longo do tempo, professores estabeleceram forte conexão com programas 
de pós-graduação em diversas instituições da região incentivando os alunos a estabelecerem-se em linhas de pesquisa a longo prazo, conectando trabalhos de iniciação científica, projetos de conclusão de curso e pesquisas a nível de mestrado e doutorado. A partir dessas iniciativas, observou-se que a disciplina de TCC passou a representar, cada vez mais, um momento de aplicação não apenas de conceitos, técnicas e ferramentas tecnológicas, mas das habilidades de projetar, especificar e gerir projetos e soluções de engenharia sejam estas provenientes do desenvolvimento de protótipos ou da pesquisa metodológica aplicada.

Apesar das diversas modificações implantadas ao longo do tempo, a metodologia de avaliação se manteve quase inalterada. $\mathrm{O}$ aluno, em diversas fases do trabalho, era avaliado por meio de notas em critérios como concordância, qualidade textual, implementação e qualidade de software ou hardware, gradados por meio de pesos que determinam a importância de cada critério para aquela fase específica, como pode ser observado por meio do formulário de avaliação utilizado até o final do ano de 2017 (Figura 1). O avaliador, além de julgar a nota para cada critério, poderia também acrescentar um desconto por modificações solicitadas pela banca e não realizadas pelo aluno em fases anteriores, bem como indicar, por meio de critérios de suficiência a aprovação ou reprovação do aluno naquela fase.

1. Identificação

Título do Trabalho:

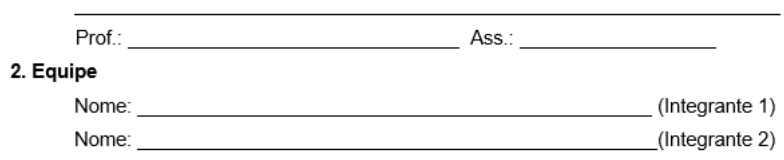

3. Avaliação

\begin{tabular}{|l|c|c|}
\hline \multicolumn{1}{|c|}{ Item Avaliado } & Peso & Avaliação \\
\hline Concordância com a Proposta aprovada do TCC & 30 & \\
\hline $\begin{array}{l}\text { Qualidade do texto } \\
\text { (ortografia, gramática, coesão e coerência) }\end{array}$ & 20 & \\
\hline $\begin{array}{l}\text { Qualidade técnica do texto } \\
\text { (conceitos, cálculos, citação de fontes etc.) }\end{array}$ & 20 & \\
\hline $\begin{array}{l}\text { Referências Bibliográficas } \\
\text { (qualidade, formatação, citação de todas as referências } \\
\text { no texto etc.) }\end{array}$ & 15 & \\
\hline Respeito às normas de formatação & 10 & \\
\hline $\begin{array}{l}\text { Elementos pré-textuais (capa, folha de rosto, resumo, } \\
\text { listas etc.) e demais Elementos pós-textuais } \\
\text { (apêndices, anexos etc.) }\end{array}$ & 5 & \\
\hline $\begin{array}{l}\text { Desconto por não ter realizado as correções da } \\
\text { avaliação anterior. }\end{array}$ & até 100\% & \\
\hline & Totais & \\
\hline
\end{tabular}

4. Conceito

SUFICIENTE $\square \begin{aligned} & \text { SUFICIENTE COM } \\ & \text { RESTRIÇÖES }\end{aligned} \quad$ INSUFICIENTE

Observaçōes do avaliador:

Figura 1: Formulário de avaliação utilizado até o final do ano letivo de 2017

Nesta abordagem, porém, não há como balizar os critérios utilizados por cada avaliador para definir sua nota, bem como o significado de tal nota no contexto da solução e implementação apresentada pelo aluno. A ausência de uma régua avaliativa se refletia na possibilidade de julgar a suficiência do trabalho sem uma conexão clara com a nota, o que permitia, por exemplo, uma avaliação suficiente, porém com nota total inferior a média institucional (nota 7), bem como a diferença de classificações entre trabalhos de mesma qualidade de implementação e uma nota com forte presença de vieses inconscientes do avaliador.

A urgência de solução para tais problemáticas, somadas à necessidade de adequação da disciplina à oferta semestral, permitiram a análise e criação de uma nova metodologia de acompanhamento e avaliação dos Trabalhos de Conclusão de Curso.

\section{PAPÉIS NO PROCESSO}

O Trabalho de Conclusão de Curso, além de uma disciplina curricular, é um processo que envolve um conjunto de papéis, como o da Comissão de TCC, Banca de Avaliação, professores avaliadores e de alunos e equipes, papéis cujo objetivo e participação no processo serão apresentados em seções individuais.

\subsection{Comissão de TCC}

A Comissão de TCC é composta pelo grupo de professores orientadores, coordenador da disciplina de TCC e coordenador de curso e tem por finalidade julgar, estabelecer e manter regras de desenvolvimento do TCC, bem como avaliar as propostas de trabalho submetidas na Fase 1.

Apesar de exercer um papel fundamental na construção da Instrução Normativa (IN), modificações que possam alterar componentes estruturais do curso são, também, julgadas e aprovadas pelo Núcleo Docente Estruturante (NDE).

\subsection{Professores Orientadores}

Os professores orientadores são escolhidos pela coordenação de curso a cada início de semestre letivo. Cada orientador é responsável pela gestão de um conjunto de equipes de trabalho, de acordo com a carga horária destinada.

\subsection{Banca de Avaliação}

A Banca de Avaliação é composta, minimamente, pelo professor orientador e dois membros de banca. Como membros de banca poderão participar: professores do curso, de outros cursos, de outras instituições ou profissionais de mercado.

A Banca de Avaliação tem papel fundamental em todas as fases do trabalho, tanto na correção de documentos quanto nas apresentações orais.

\subsection{Equipes de trabalho}

A fim de promover habilidades interpessoais, o trabalho em equipe é um fator determinando na proposta de trabalhos. Deste modo, como regra, os alunos devem agrupar-se em duplas; qualquer outro número para composição das equipes deve ser justificada e estará sujeita a aprovação pela Comissão de TCC.

Ainda, incentiva-se o trabalho multidisciplinar, promovendo a composição de trabalhos complementares pelo agrupamento de equipes de múltiplos cursos a fim de obter um objetivo, metodologia ou protótipo único. Nestes casos, cada aluno de cada equipe, em 
cada curso, é orientado e avaliado perante regras de seu curso, garantindo a avaliação transparente e sem prejuízos aos alunos.

\section{MODELO DE AVALIAÇÃO}

As avaliações do TCC têm por objetivo principal analisar o desenvolvimento das competências adquiridas pelo aluno ao longo do processo educacional. Para tal, a cada fase do TCC o aluno é avaliado por meio de uma ou mais rubricas, composta por critérios de avaliação e níveis e de conhecimento. É importante ressaltar que, apesar da formação de equipes ao longo do TCC, os processos avaliativos são individualizados, sendo possível, por exemplo, a aprovação de um elemento de equipe e a reprovação de outro.

Como mostra a Figura 2, a rubrica é apresentada em forma de quadro ou tabela, na qual há uma linha para cada critério e uma coluna para cada nível. Cada célula da tabela apresenta uma descrição correspondente ao nível de conhecimento. Assim, o preenchimento da rubrica é feito selecionando um nível de conhecimento para cada critério de avaliação.

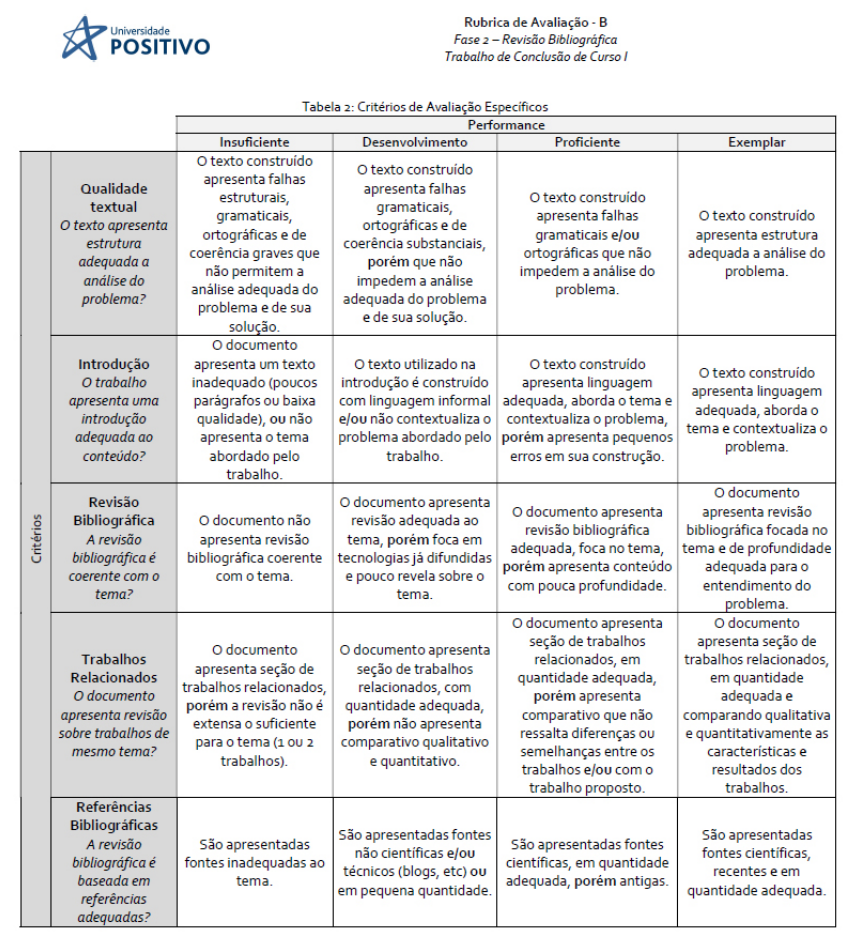

Figura 2: Rubrica de Critérios de Avaliação Específicos da fase de Revisão Bibliográfica

Em cada fase do TCC há um conjunto de critérios (entre 4 e 8), necessários para alcançar uma ou mais competências, parcial ou completamente. Cada critério é descrito por 4 níveis de performance/conhecimento, sendo eles "Insuficiente", "Em Desenvolvimento", "Proficiente" e "Exemplar".

O nível "Insuficiente", em qualquer critério de avaliação, representa atitudes e habilidades classificadas como não adequadas ao aluno neste nível de maturidade no curso, como a incapacidade de construção de um texto coerente com o tema, ou a presença de falhas graves na descrição funcional do protótipo ou metodologia especificados.

O nível "Em Desenvolvimento" representa a criação e descrição de um projeto suficiente, ou seja, as falhas presentes ao longo do processo e/ou do documento, não impedem a análise da solução, apesar de revelarem que o aluno não alcançou ou desenvolveu as competências necessárias para esta fase.

O nível "Proficiente" representa a criação e descrição adequada do projeto, porém com a presença de erros de menor importância e que poderiam revelar a desatenção a detalhes superficiais, como a inexistência de planos de gestão de problemas, de tempo ou a presença de erros textuais breves. O nível "Exemplar", por fim, representa a compreensão e incorporação da competência descrita pelo critério, o que indica o desenvolvimento de um trabalho em seu nível de excelência.

Para que seja possível seu registro no sistema acadêmico, os níveis de performance são traduzidos levando em consideração os conceitos "Aprovado", "Suficiente com Restrições" e "Reprovado", para os quais não há equivalência numérica.

O nível "Reprovado" é atingido quando o trabalho é classificado como "Insuficiente" em qualquer quantidade, critério de avaliação específico ou fase de desenvolvimento. Este conceito também é atribuído a equipe que não cumprir o prazo de revisão dos trabalhos ou prazos estipulados pelo calendário acadêmico.

O conceito "Suficiente com Restrições" é atribuído as equipes cujos trabalhos obtiveram $70 \%$ das avaliações em nível menor ou igual a "Proficiente" (e nenhum em "Insuficiente").

O conceito "Aprovado" é atribuído, portanto, a aqueles que atingirem $70 \%$ das avaliações em nível "Exemplar" e nenhum critério for avaliado em "Em Desenvolvimento".

Para evitar que critérios relativos, por exemplo, a inequação do trabalho ao formato determinado pelo curso ou pela biblioteca central, levem à reprovação sumária do trabalho, cada rubrica é composta por dois tipos de critérios de avaliação, os gerais e específicos. Os critérios de avaliação específicos, seguem o protocolo de avaliação padrão, enquanto os critérios de avaliação gerais impõem um prazo de correção antes da decisão pela reprovação.

\section{ETAPAS DO TCC}

A disciplina de TCC é dividida em 5 etapas que coincidem com, porém não se limitam a, fragmentos dos capítulos do documento final, observando etapas de um projeto.

\subsection{Fase 1 - Proposta}

Na primeira etapa as equipes devem entregar a proposta de trabalho e, deste modo, a Fase 1 recebe o nome de "Proposta".

A proposta é um documento formal, entregue pelos aluno à Comissão de TCC, que contém o título do trabalho e seu tipo (projeto de protótipo ou de pesquisa), a proposta de trabalho na qual devem ser descritos o problema a ser solucionado, justificativa, breve explicação e representação gráfica da solução esperada; objetivos geral e específicos, a descrição de recursos e custos estimados, bem como o cronograma de trabalho que deve abranger as etapas formais da disciplina e marcos do projeto.

Cada proposta é analisada por uma dupla de professores que compõem a Comissão de TCC e avaliada conforme critérios de avaliação 
gerais e específicos. Na Fase 1, compõem os critérios de avaliação gerais a adequação da proposta ao modelo de documento estipulado pela Comissão, a adequação do título, aderência do trabalho ao tipo de projeto e ao tema escolhido e a existência de indícios de fraude acadêmica. Compõem os critérios de avaliação específicos da Fase 1 a qualidade textual do documento, o reconhecimento de aspectos relevantes e necessários do problema, a elaboração de um modelo adequado para sua solução, a redação de objetivos geral e específicos capazes de representar a solução do problema e elaboração de um cronograma adequado à solução proposta.

As propostas podem ser classificadas em níveis: "Reprovada", critério que reprova a proposta dos alunos e proíbe a ressubmissão da ideia; "Aprovada com restrições", critério que aprova a proposta, porém a sujeita a correção de erros de escopo ou textuais; e "Aprovada”, que aprova a proposta sem modificações. Os alunos têm a possibilidade de submeter diversas propostas (normalmente entre 2 e 4) para análise ao longo do prazo desta fase. Caso nenhuma das propostas submetidas seja aprovada, a Comissão de TCC indica um tema de trabalho à equipe. Caso o aluno não aceite a indicação, ou não cumpra os prazos estabelecidos em calendário, determina-se sua reprovação e recomenda-se o cancelamento da disciplina.

\subsection{Fase 2 - Revisão Bibliográfica}

Com propostas de trabalho aprovadas inicia-se a Fase 2, na qual espera-se que os alunos construam os capítulos de Introdução e Revisão Bibliográfica do documento. A Introdução segue uma estrutura bem definida e conhecida metodologicamente, na qual são descritos o problema, seu contexto e justificativa de solução, seguidas pelos objetivos do projeto. Na revisão Bibliográfica, indica-se aos autores a composição de um texto que contextualize o problema e aprofunde aspectos tecnológicos pertinentes, evitando a apresentação de tecnologias extremamente difundidas. Espera-se, ainda, uma seção de trabalhos relacionados, através da qual seja possível criar uma comparação qualitativa, e/ou quantitativa, e uma discussão sobre seus resultados.

A partir da Fase 2, os critérios de avaliação gerais são padronizados e passam a abranger apenas a adequação do trabalho ao formato e a existência de indícios de fraude acadêmica. Tal mudança ocorre devido ao fato de que a partir desta fase a insuficiência de alguma avaliação específica incide na reprovação da equipe, portanto, aspectos gerais podem ser avaliados de forma mais branda, permitindo a equipe a adequação em um prazo delimitado. Os critérios de avaliação Gerais, ainda, são analisados por meio de apenas dois critérios de performance: insuficiente ou proficiente.

Os critérios de avaliação específicos da Fase 2 permitem avaliar a qualidade textual empregada na construção do documento, a adequação da abordagem de construção da introdução e sua contextualização do problema, a pertinência da revisão bibliográfica, sua profundidade e foco, a presença de uma revisão profunda de trabalhos relacionados, incorporando aspectos qualitativos e quantitativos de cada trabalho e uma discussão sobre seus resultados, bem como o uso de fontes científicas, recentes e em quantidade adequada para compor a bibliografia do documento.

\subsection{Fase 3 - Especificação Técnica ou Metodologia de Pesquisa}

A Fase 3 está destinada a composição do capítulo de projeto do protótipo ou da metodologia de pesquisa, de acordo com o tipo de trabalho ao qual a equipe esteja se dedicando.

A especificação técnica é destinada aos trabalhos de construção de protótipo e tem por objetivo a descrição detalhada da análise de contexto ao qual o problema e solução estão inseridos, da análise funcional e de requisitos tecnológicos, bem como da análise da arquitetura do sistema proposto. Neste momento observa-se a capacidade do aluno de analisar e descrever condições restritivas, benefícios e impactos da implantação da solução frente à contextos sociais, políticos, ambientais e econômicos. Avalia-se ainda, a capacidade de análise e descrição das funcionalidades, protocolos e sistemas de comunicação, processamento, controle e atuação de forma clara, seja por meio escrito ou gráfico, utilizando diagramas relacionados.

A metodologia de pesquisa, por sua vez, é específica para trabalhos do tipo "projeto de pesquisa", tendo por objetivo a descrição do objeto de pesquisa, população ou amostra, metodologia de coleta e análise de dados, bem como a descrição de protótipos necessários para a execução da metodologia. Nesta fase, as rubricas de avaliação descrevem critérios que analisam a capacidade do aluno de definir e apresentar, de forma clara e específica, o objeto de pesquisa, definir população ou amostra de estudo (levando em consideração critérios de seleção adequados), definir um processo de coleta de dados preciso e, por fim, uma metodologia de análise que compreenda ferramentas e algoritmos adequados ao objetivo.

Devido à oferta semestral do TCC, esta também é a fase que demarca o encerramento do primeiro semestre, ou disciplina. Além da entrega do documento que descreve o problema, seu contexto e a metodologia que será aplicada para sua solução, as equipes devem apresentar suas percepções sobre o trabalho em uma apresentação oral pública. Neste momento, os alunos são questionados pela Banca de Avaliação, principalmente, sobre a especificação ou metodologia descrita pela equipe de modo a alavancar uma reflexão sobre o processo de desenvolvimento a ser adotado ao longo do próximo semestre.

Ao longo da apresentação, são avaliadas a qualidade e capacidade dos alunos de apresentarem o conteúdo e responder à questionamentos, bem como são avaliados critérios relacionados à oratória (vocalização, ritmo, contato visual, imagem pessoal e preparação).

\subsection{Fase 4 - Desenvolvimento e Qualificação}

A Fase 4 representa o período, oficial, de desenvolvimento da pesquisa e do protótipo descritos pelo documento apresentado na fase anterior. Em geral esta fase tem duração de 2,5 a 3 meses, dependendo da organização do calendário acadêmico e é finalizada pela entrega de um capítulo que descreve o processo de desenvolvimento do protótipo ou da aplicação de coleta de dados e de uma análise mínima dos resultados obtidos. Estas informações são validadas por uma apresentação dos resultados obtidos nesta fase.

Os trabalhos do tipo protótipo são avaliados pela qualidade do protótipo de hardware e/ou software apresentados, espera-se que o protótipo esteja concluído e funcionando de maneira apropriada e 
adequada, bem como tenha sido construído seguindo as especificações descritas por documento anterior e boas práticas de construção de hardware e software.

Os trabalhos do tipo "projeto de pesquisa" são avaliados pela implantação de todas as etapas descritas para a metodologia de coleta de dados, observando critérios éticos, e uma breve descrição dos resultados primários obtidos por meio desta coleta.

\subsection{Fase 5 - Defesa Pública}

A fase 5 demarca a entrega final da documentação do TCC, sua defesa pública formal e a apresentação em workshop institucional.

Nesta fase as equipes devem elaborar os capítulos finais do documento de TCC no qual descrevem testes, resultados e conclusões. Espera-se que, em trabalhos de desenvolvimento de protótipo, os alunos descrevam metodologias e resultados de testes que apresentem a qualidade do protótipo produzido, bem como validem a solução do problema. Já em trabalhos do tipo "projeto de pesquisa" os alunos devem apresentar uma descrição detalhada do processo de análise de dados.

São avaliados, neste momento, critérios relacionados a capacidade dos alunos em descrever a metodologia de testes de forma clara e coerente com os objetivos do trabalho, apresentar resultados e uma discussão qualitativa ou quantitativa pertinente, capaz de afirmar aspectos observados pela equipe, sem apresentar tendências pessoais, bem como considerar os objetivos do trabalho a fim de embasar um conclusão que comprove ou refute a hipótese ou a validade da solução desenvolvida. As equipes, ainda, são avaliadas por seu desempenho em apresentação oral, utilizando os mesmos critérios descritos pela rubrica da fase 3 .

\section{PROCESSO DE MELHORIA CONTÍNUA}

A cada ciclo de trabalho, indicado pelo término do semestre, o processo e as rubricas de avaliação, bem como as regras que norteiam a execução do TCC, são analisadas. Tal análise é realizada pelo Comitê de TCC que reúne as considerações dos professores avaliadores e orientadores deliberando a modificação dos documentos de base.

São avaliados os critérios de classificação das rubricas em cada nível de performance e indicadores de habilidades. Este é um processo essencial, pois devido a dinâmica da tecnologia e a grande diversidade de temas pode ser necessário a alteração ou inclusão de determinados requisitos.

O modelo de documento é readequado para garantir o cumprimento de regras institucionais e renovar metodologias de desenvolvimento de projetos tecnológicos. Ainda, as regras de avaliação pertinentes à IN também são balanceadas conforme a necessidade. Estas regras, porém, são encaminhadas para análise do NDE que aprova ou reprova a alteração da IN.

\section{RESULTADOS}

A metodologia foi aplicada nos anos de 2018, 2019 e 2020, atingindo 83 estudantes em 47 equipes de trabalho, além de 12 professores dentre professores orientadores e componentes de banca de avaliação.

Das 13 equipes de trabalho (24 alunos) que iniciaram o TCC em 2018, houveram 3 trabalhos reprovados durante o processo
Tabela 1: Pesquisa com alunos

\begin{tabular}{|c|c|c|}
\hline Pergunta & Pontuação & Desvio Padrão \\
\hline $\begin{array}{l}\text { Como você avalia a importância } \\
\text { dos tipos de trabalhos, com seus } \\
\text { modelos e elementos individuais, } \\
\text { na produção do Projeto Final de } \\
\text { Curso? }\end{array}$ & 8,36 & 1,55 \\
\hline $\begin{array}{l}\text { Como você avalia a existência de } \\
\text { linhas de pesquisa e áreas de apli- } \\
\text { cação na execução do Projeto Fi- } \\
\text { nal de Curso? }\end{array}$ & 5,21 & 3,33 \\
\hline $\begin{array}{l}\text { Como você avalia a organiza- } \\
\text { ção das fases do Projeto Final de } \\
\text { Curso? }\end{array}$ & 7,00 & 2,63 \\
\hline $\begin{array}{l}\text { Como você avalia os prazos de en- } \\
\text { trega das atividades de cada fase? }\end{array}$ & 5,36 & 2,37 \\
\hline $\begin{array}{l}\text { Como você avalia a existência de } \\
\text { rubricas para avaliação de cada } \\
\text { uma das fases do TCC? }\end{array}$ & 7,43 & 2,47 \\
\hline $\begin{array}{l}\text { Como você avalia conexão entre } \\
\text { os critérios de avaliação e fases do } \\
\text { TCC, em cada uma das rubricas? }\end{array}$ & 8,07 & 1,49 \\
\hline $\begin{array}{l}\text { Como você avalia a clareza dos } \\
\text { indicadores de desempenho dos } \\
\text { critérios de avaliação das rubri- } \\
\text { cas? }\end{array}$ & 7,93 & 1,33 \\
\hline $\begin{array}{l}\text { Ao receber um feedback de uma } \\
\text { avaliação por meio das rubricas } \\
\text { de TCC consigo identificar o que } \\
\text { devo melhorar. }\end{array}$ & 7,14 & 1,10 \\
\hline
\end{tabular}

utilizando a metodologia de rubricas. Na avaliação das equipes de trabalho no ano de 2019, 26 estudantes iniciaram o TCC, sendo que 4 destes foram reprovadas através do método de rubricas nas diversas fases. No ano de 2020 o processo de avaliação ainda não foi finalizado, mas o número de estudantes que iniciaram o processo de TCC foram 33, sendo que até a fase 4 houveram 2 reprovações.

Para a análise dos resultados da metodologia apresentada neste trabalho, foi aplicado um questionário junto aos professores que estão participando ativamente no processo nos anos de 2018, 2019 e 2020 e estudantes participantes do TCC em 2020, todos tendo papel de alunos nas equipes de trabalho, professores orientadores ou bancas de avaliação.

Para os alunos, foi aplicado o questionário contendo as perguntas mostradas na Tabela 1, sendo nesta mesma tabela mostrada a pontuação média para cada uma das repostas, que poderia ser entre 0 e 10, e o respectivo desvio padrão. Treze alunos responderam à pesquisa anonimamente.

Apoiando-se nos dados obtidos pela pesquisa, observa-se que entre os pontos mais críticos na percepção do aluno estão a presença de linhas de pesquisa $(5,21)$ e os prazos de entrega $(5,36)$. Entre os pontos melhor avaliados estão a importância dos tipos de trabalho de pesquisa e protótipo $(8,36)$ e a conexão entre os critérios de avaliação e as fases $(8,07)$. É importante observar, neste ponto, que 
Tabela 2: Pesquisa com professores

\begin{tabular}{|c|c|c|}
\hline Pergunta & Pontuação & Desvio Padrão \\
\hline $\begin{array}{l}\text { Como você avalia a importância } \\
\text { dos tipos de trabalhos, com seus } \\
\text { modelos e elementos individuais, } \\
\text { na produção do Projeto Final de } \\
\text { Curso? }\end{array}$ & 8,00 & 3,00 \\
\hline $\begin{array}{l}\text { Como você avalia a existência de } \\
\text { linhas de pesquisa e áreas de apli- } \\
\text { cação na execução do Projeto Fi- } \\
\text { nal de Curso? }\end{array}$ & 8,00 & 1,90 \\
\hline $\begin{array}{l}\text { Como você avalia a organiza- } \\
\text { ção das fases do Projeto Final de } \\
\text { Curso? }\end{array}$ & 8,67 & 1,97 \\
\hline $\begin{array}{l}\text { Como você avalia os prazos de en- } \\
\text { trega das atividades de cada fase? }\end{array}$ & 8,33 & 1,20 \\
\hline $\begin{array}{l}\text { Como você avalia a existência de } \\
\text { rubricas para avaliação de cada } \\
\text { uma das fases do TCC? }\end{array}$ & 8,50 & 3,20 \\
\hline $\begin{array}{l}\text { Como você avalia conexão entre } \\
\text { os critérios de avaliação e fases do } \\
\text { TCC, em cada uma das rubricas? }\end{array}$ & 8,17 & 1,72 \\
\hline $\begin{array}{l}\text { Qual o nível de confiança na utili- } \\
\text { zação de um indicador de desem- } \\
\text { penho na avaliação de um aluno? }\end{array}$ & 7,17 & 2,14 \\
\hline $\begin{array}{l}\text { Como você avalia o novo pro- } \\
\text { cesso de TCC em comparação ao } \\
\text { modelo antigo levando em consi- } \\
\text { deração o processo de avaliação? }\end{array}$ & 8,33 & 2,34 \\
\hline
\end{tabular}

a avaliação revela uma certa incoerência em relação à compreensão da conexão entre linhas de pesquisa e tipos de trabalho, avaliados aqui de forma bastante discrepante, já que os projetos de pesquisa, por exemplo, necessitam de áreas norteadoras concentradas nas áreas de expertise do corpo docente.

O questionário dos alunos ainda oferecia um campo para comentários, sendo que os comentários referentes à metodologia adotada foram positivos, ressaltando apenas um comentário que indicou que as rubricas poderiam ter pesos diferentes para as diversas fases do TCC, pois algumas fases têm importância maior que outras. Foi sugerido em um comentário, que esta é uma forma inovadora de avaliação, diferente das aplicadas em outras instituições. Outros comentários indicaram que o tempo de desenvolvimento de cada fase poderia ser maior e que as linhas de pesquisa poderiam ser mais abrangentes, o que não está relacionado à questão da metodologia apresentada neste trabalho.

Para os professores foi aplicado um questionário similar, com as perguntas mostradas na Tabela 2, sendo nesta mesma tabela mostrada a pontuação média para cada uma das respostas, que poderia ser entre 0 e 10, e o respectivo desvio padrão. Sete professores responderam à pesquisa.

A avaliação da metodologia, pelo corpo docente, revelou importantes características. De modo geral, pode-se notar que a pontuação média dos aspectos observados é superior a pontuação obtida por meio da avaliação dos discentes. Como pontos de destaque estão a organização das fases $(8,67)$ e a existência de rubricas $(8,50)$. Alguma discordância, porém, se revela em questões sobre a importância dos tipos de trabalhos, que apresenta desvio padrão relevante $(3,00)$ e nota média inferior a avaliação dos alunos. Tal comportamento pode ser explicado pelo forte posicionamento institucional para uma formação ligada ao mercado de trabalho, o que, na visão de muitos professores, não abre caminho para a pesquisa acadêmica. Essa avaliação também se repete, com menor intensidade porém, no nível de confiança na utilização dos indicadores $(7,17)$ e, neste ponto, cabe observar que os docentes foram mais críticos que os alunos se comparado o nível de confiança à percepção de clareza dos indicadores (questionário dos alunos).

No campo de comentários gerais, foi citado que o formato é considerado adequado e promissor, mas que necessita de um tempo para amadurecimento com a possibilidade de melhorias conforme necessário. Além disso foi feita a observação de que houve uma melhora significativa na objetividade da avaliação, principalmente no que se refere a avaliação por múltiplos professores. Outro professor relatou que o processo de avaliação tornou-se mais transparente, uma vez que o aluno passou a ter conhecimento de forma clara em qual critério ele falhou ou acertou, mas que muitas vezes os alunos não fazem uso delas buscando a adequação e melhoria do trabalho. Apenas um professor acredita que o modelo não necessariamente agrega valor ao TCC, gerando muito trabalho aos envolvidos. O mesmo também acredita que deveria haver menos bancas e entregas no processo.

\section{CONCLUSÃO}

Por meio do processo apresentado neste trabalho, procura-se fechar um ciclo no qual o estudante teve a oportunidade de melhorar seu desempenho, seu conhecimento e sua capacidade profissional e pessoal em vários aspectos como resiliência, capacidade técnica, interpretação, multidisciplinaridade e melhoria contínua.

No que tange o resultado das pesquisas da aplicação da metodologia, as notas dadas às perguntas referentes à metodologia em si (perguntas relacionadas às rubricas), pelos professores e alunos, se mostraram boas. O resultado também mostrou que o processo deve ser apoiado e melhorado constantemente, como está sendo executado no processo de melhoria contínua aplicado na metodologia.

Foi observado, também, através das pesquisas realizadas, que os alunos devem se apoiar mais nos resultados e comentários das rubricas para melhorar o seu trabalho, o que pode ser realizado com uma campanha de conscientização no início do projeto de TCC.

\section{REFERÊNCIAS}

[1] ABNT. 2011. NBR 14724 - Informação e documentação - Trabalhos acadêmicos Apresentação. ABNT, Rio de Janeiro.

[2] Eduardo Alberti, Adriano Targa, Glavio Paura, and Alessandro Brawerman. 2018. Evaluating Active Learning Methodologies in a Computer Engineering Programa. In 12th International Technology, Education and Development Conference. IATED, Valencia, 8408-8414. https://doi.org/10.21125/inted.2018.2036

[3] Eduardo Juliano Alberti, Felipe Augusto Przysiada, Alessandro Brawerman, and Maurício Perretto. 2007. Multidisciplinares No Curso De Engenharia Da Computação. In Anais do XXXIX Congresso Brasileiro de Educação em Engenharia. ABENGE, Blumenau, 1-10.

[4] Edilson Carlos Caritá, Carmen Silvia Gonçalves Lopes, Silvia Sidnéia da Silva, and Neide Aparecida de Souza Lehfeld. 2019. Avaliação da aprendizagem por meio de rubrica em curso de engenharia de produção/Assessment of learning through 
ongoing production engineering rubric. Brazilian fournal of Development 5, 9 (2019), 14911-14921.

[5] Ciliana Regina Colombo and Marcos Jorge Santana Jorge. 2006. TRABALHOS DE CONCLUSÃO DE CURSO : Um Meio de Fomentar um Processo de Ensino de Engenharia Baseado em Pesquisa. In Anais do XXXIV Cobenge: Passo Fundo. ABENGE, Passo Fundo, 20-28.

[6] Edison José Corrêa, Mara Vasconcelos, and Maria Suzana de Lemos Souza. 2018 Iniciação à metodologia : Trabalho de Conclusão de Curso. NESCON UFMG, Belo Horizonte.

[7] Tiago da Rosa Santos, Eduardo Pazini, and Avanilde Kemczinski. 2020. Um mapeamento sistemático da literatura sobre a avaliação em pares das competências de um indivíduo em uma equipe de projetos de software. iSys-Revista Brasileira de Sistemas de Informação 13, 3 (2020), 98-131.

[8] Márcia Gonçalves de Oliveira, Leonardo Leal Reblin, Mateus Batista de Souza, and Elias Oliveira. 2018. Reconhecimento automático de representações de rubricas em agrupamentos de soluções de exercícios de programação. Revista Brasileira de Informática na Educação 26, 02 (2018), 60.

[9] Ana Paula do Carmo Marcheti. 2020. RUBRICAS: um importante instrumento para correção de desempenho discente. Revista Eletrônica Científica Ensino Interdisciplinar 6, 16 (2020), 58-76.

[10] Edson Pedro Ferlin. 2001. The computer Engineering Project Course. In International Conference on Engineering Education. WASET, Oslo, Norway, 6B5,17-19.
[11] Rosina Paula Ferracciú Ferraz et al. 2019. Avaliação como processo de aprendizagem: uma experiência com o uso de rubrica. Master's thesis. Pontifícia Universidade Católica de São Paulo.

[12] Tiago Oliveira, Denise Stringhini, José Jailson Santos Craibas, and Deborah Godoy Martins Corrêa. 2020. Desenvolvimento da Habilidade de Escrita de Relatórios Técnicos Utilizando Avaliações Colaborativas e Rubricas. Revista Brasileira de Informática na Educação 28 (2020), 166.

[13] Valfredo Pilla Jr and Edson Pedro Ferlin. 2011. Os níveis de aprendizagem da taxonomia de bloom aplicados em uma disciplina de um curso de engenharia da computação. In Anais do XXXIX Congresso Brasileiro de Educação em Engenharia. ABENGE, Blumenau, 1-6.

[14] Gianna Oliveira Bogossian Roque, Marcos da Fonseca Elia, and Claudia Lage Rebello da Motta. 2006. Utilização de rubricas na avaliação da aprendizagem em atividades desenvolvidas a distância. In Anais do Workshop de Informática na Escola, Vol. 1.

[15] Alberto A. Shiga and Carlos A. G. Pegollo. 2002. A Multidisciplinaridade como forma de Motivação para os novos alunos de Engenharia. In Anais do XXXI Cobenge: Rio de faneiro. Abenge, Rio de Janeiro.

[16] Maristela R Weinfurter Teixeira, José Carlos da Cunha, Ederson Cichaczewski, Giancarlo de França Aguiar, and Edson Pedro Ferlin. 2010. Situações-problema como prática de Multi, Inter e Transdisciplinaridade na Engenharia da Computação da Universidade Positivo. In Anais do XXXVIII Congresso Brasileiro de Educação em Engenharia. ABENGE, Fortaleza, 1-6. 